\title{
Diferenças no Perfil Trombofilico de Mulheres com Antecedente de Tromboembolismo Venoso Relacionado e não Relacionado com a Terapia de Reposição Hormonal
}

Differences in the Thrombophilic Profile of Women with a History of Venous Thromboembolism Related and Unrelated to Hormone Replacement Therapy

Paulo Francisco Ramos Margarido, Sérgio Paulo Bydlowski, Vicente Renato Bagnoli, Ângela Maggio Da Fonseca, José Aristodemo Pinotti

Hospital das Clinicas da Faculdade de Medicina da USP

Objetivos: no presente estudo procurou-se avaliar se há diferenças nos fatores de risco presentes em mulheres que desenvolvem doença tromboembólica em uso ou não da terapia de reposição hormonal, principalmente através da pesquisa dos fatores trombofilicos.

Casuística e Métodos: foram avaliadas 34 mulheres com antecedente de tromboembolismo venoso comprovado, sendo que 11 delas (Grupo A) manifestaram a doença venosa na vigência da terapia de reposição hormonal e que foram comparadas às outras 23 (Grupo B). Foi considerada a primeira manifestação da doença venosa, apenas. Realizou-se a pesquisa das deficiencias de proteina $C$, proteina $S$ e antitrombina III, bem como a pesquisa das mutações R506Q do fator V (fator V de Leiden), G20210A da protrombina e C677T da enzima metilenotetraidrofolatoredutase. Foi também pesquisada a presença de anticorpos antifosfolipides (anticoagulante lúpico e anticorpos anticardiolipina).

Resultados: As pacientes que manifestaram tromboembolismo venoso em uso da terapia de reposição hormonal apresentaram idade significativamente maior de ocorrência da

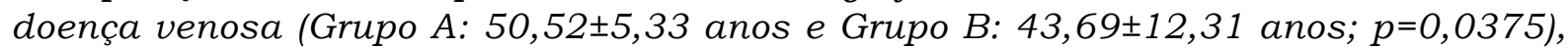
além de tendência a maior número de fatores trombofílicos presentes $(p=0,069)$ e de associações entre estes ( $p=0,102)$.

Discussão: estes dados sugerem que pode haver influência destes fatores no risco relativo de tromboembolismo venoso atribuido à terapia de reposição hormonal pelos estudos populacionais. Além disto, mulheres que manifestam tromboembolismo venoso em uso da reposição hormonal devem ser investigadas quanto à presença de fatores trombofílicos, devido à sua possivel alta prevalência neste grupo.

PALAVRAS-CHAVE: Terapia de Reposição Hormonal. Tromboembolismo. Menopausa. 